\title{
Maternal-child co-participation in physical activity-related behaviours: prevalence and cross-sectional associations with mothers and children's objectively assessed physical activity levels
}

Jill A. Hnatiuk ${ }^{1,2^{*}}$, Ellen DeDecker ${ }^{3}$, Kylie D. Hesketh ${ }^{1}$ and Greet Cardon ${ }^{3}$

\begin{abstract}
Background: Co-participation in physical activity may be a useful strategy for increasing physical activity in mothers and their young children, yet little empirical evidence exists on this topic for young families. This study aimed to identify the prevalence of mother-child co-participation in physical activity and examine the association between co-participatory behaviours and objectively-assessed physical activity in young children and their mothers.

Methods: One-hundred twenty-three 4-6 year-old children and their mothers were recruited from preschools in Belgium between November 2010 and January 2011. Mothers completed a questionnaire assessing the frequency of co-participation in five activities. Both mothers and children wore ActiGraph GT1M accelerometers concurrently for 7 days to assess the time spent in moderate-to vigorous-intensity physical activity (MVPA) and light- to vigorous-intensity physical activity (LMVPA). Descriptive statistics (means, frequencies) were used to determine the prevalence of coparticipation. Separate multiple linear regression analyses examined the association between co-participation and mothers' and children's physical activity on weekdays and weekends.

Results: Most mothers reported infrequent co-participation in physical activities with their children. On weekdays, walking or cycling for short trips was positively associated with children's MVPA while attending a park or similar more than once per week was negatively associated with children's MVPA and LMVPA. Going to an indoor play centre together once or more per week was negatively associated with mother's LMVPA. On weekends, walking or cycling with their child in their free time was positively associated with both children's and mothers' MVPA and childrens' LMVPA. Going to an indoor play centre together 1-3 times/month was negatively associated with children's weekend MVPA.

Conclusions: Reported rates of co-participation in mothers and their preschool children were low. The association with maternal and child physical activity may be dependent on the co-participatory behaviour assessed and may differ between weekday and weekends. Promoting walking and cycling together during leisure time may be an effective strategy to increase both preschool children's and mothers' MVPA.
\end{abstract}

Keywords: Motor activity, Mother-child relations, Preschool child

\footnotetext{
* Correspondence: jill.hnatiuk@deakin.edu.au

'Institute for Physical Activity and Nutrition (IPAN), School of Exercise and

Nutrition Sciences, Deakin University, Geelong, Australia

${ }^{2}$ School of Science and Health, Western Sydney University, Locked Bag 1797,

Penrith, NSW 2150, Australia

Full list of author information is available at the end of the article
} 


\section{Background}

It is well-established that regular participation in physical activity is important for health across the lifespan. Strong evidence exists for the benefits of physical activity on chronic disease risk factors in adults [1] and increasing evidence is emerging in young children [2]. One adult demographic group previously identified as at risk of low physical activity levels is parents of young children ( $<6$ years) [3]. This is particularly evident among mothers of young children, with research suggesting they are $69 \%$ less likely to meet physical activity recommendations than adults without dependent children [4]. Although the literature is mixed at present with regard to the proportion of young children who are sufficiently active [5], the high prevalence of inactivity by the time children reach primary school $[6,7]$ and the progressive decline that occurs in late childhood and adolescence, [8] suggests that the promotion of physical activity in the early years is desirable.

Given this, there is increasing interest in identifying efficient and effective strategies to increase physical activity amongst multiple family members [9]. One possible strategy to increase physical activity in both parents and children is through parent-child participation in physical activity together (co-participation). Based on the socialcognitive theory family perspective [10] it can by hypothesised that co-participation in physical activity be beneficial for physical activity levels of both parents and children through role modelling of the behaviour (predominantly from parents to children) and/or employing reciprocal reinforcement from both parties to foster active pursuits (parents facilitating children's physical activity and vice versa). This reciprocal reinforcement may also increase the likelihood of continuity of the behaviour within the family over time [11].

For families with young children, co-participation would predominantly occur through co-engagement in active play, active transport or sport. However, there is little evidence on the prevalence of co-participation in the population as well as how it is related to objectivelymeasured physical activity levels. Several studies involving older children have found that parents and children participate in some physical activity together during the week [12-14] and that parent-child [14-16] or family $[15,17]$ co-participation in physical activity is associated with higher child physical activity levels across the week. Most research conducted with preschool aged children and their parents have focused on associations between parent/child physical activity [18-20] but haven't specifically examined whether this physical activity was performed together. Additionally, nearly all studies examining co-participation have focused on the influence that parent-child co-participation has on children's physical activity levels. Whilst this is important, understanding the role that co-participation has on parents' physical activity is warranted, as it could assist parents, particularly mothers of young children (a group traditionally at risk of low physical activity levels $[4,21])$, to meet physical activity recommendations. Given that co-participation in physical activity is greatest in families when children are in the early childhood years [22], the role of this behaviour may be particularly important during this period of time. Therefore, the aims of the present study were to: 1 ) examine the prevalence of coparticipation in mother-child pairs, and 2) determine the association between co-participation and mothers' and young children's physical activity levels.

\section{Methods}

Mothers and children were recruited from preschools in East-Flanders, Belgium between November 2010 and January 2011 as part of a broader study. Principals from 20 preschools were contacted by telephone; all agreed for their school to take part. A letter and informed consent form was then sent home with all children. Mothers of 188 4-6 year-old children provided written consent to take part in the project (response rate: 34\%). Research staff visited the preschools, fitted children with accelerometers and provided an envelope for the child to take home to their mother (containing the mothers' accelerometer, accelerometer instruction sheet, and a questionnaire). Ethics approval for this study was obtained by the Ethics Committee of the University Hospital of Ghent (EC/2006/476).

The child's mother completed a questionnaire regarding demographic and physical activity-related coparticipation behaviours. The demographic variables assessed included: child age (determined by child's date of birth); child sex; whether the child was attending preschool full-time, maternal age (determined by mothers' date of birth), education (low = secondary school or less; medium = vocational trade/certificate; high = university degree or higher) and BMI [23], number of siblings in the household (open-ended response) and language predominantly spoken at home (Dutch vs. other).

Questions assessing maternal-child co-participation were purpose-designed and included the frequency of: walking or cycling with their child in their free time $(1=$ never, $5=$ always $)$, playing sport with their child $(1=$ never, $5=$ always $)$ going to the park, playground, beach or similar with their child $(1=$ never; $10=>5$ days per week), going to indoor recreation centre with their child $(1=$ never; $10=>5$ days per week). It also assessed the mode of transport used for short trips $(<1 \mathrm{~km})$ with their child (public transport, car, walk, cycle). Due to few responses in extreme categories, those activities scored on a 5-point scale were combined into three groups: never/ seldom (1-2), sometimes (3) and often/always (4-5). 
Activities scored on a 10-point scale were also combined into 3 groups: < once per month (1-5); $1-3$ times per month (6-7); $\geq$ once per week (8-10). The mode of transport for short trips was dichotomized into active (walking, cycling) and inactive (car) as no participants indicated that they mainly used public transport for short trips.

Children's physical activity was assessed every 15-s using ActiGraph GT1M accelerometers. Children were instructed to wear the activity monitors during all waking hours for seven consecutive days, removing only for sleeping and water-based activities. Twentyminutes of consecutive zero counts were considered non-wear. Children were included in the final analyses if they had a minimum wear time of $6 \mathrm{~h} /$ day for at least 3 weekdays and 1 weekend day [24]. The average daily time spent in weekday and weekend day LMVPA and MVPA was determined by applying Pate cut-points (LMVPA $=>35$ counts $/ 15$ s; MVPA $\geq 420$ counts/15 s) [25]. These two intensities were examined since children's age at the time of data collection spanned two different sets of physical activity recommendations [26, 27] and because light-intensity physical activity may be a common intensity when parents are engaging in physical activity with their young children [28]. Weekdays and weekend days were examined separately as nearly all children of this age in Belgium attend preschool full time (e.g. 8 am-4 pm) [29]. Thus the opportunity for maternal-child coparticipation in physical activity would potentially be greater on weekends compared to weekdays.

Mothers' physical activity was assessed every 60-s using ActiGraph GT1M accelerometers during waking hours over the same days that their child wore the monitors. Twenty-minutes of consecutive zero counts were considered non-wear. Freedson cut-points [30] were applied to the data to determine the average daily time spent in MVPA during weekdays and weekend days separately $(\geq 10 \mathrm{~h} /$ day). Mothers were only included in the final analyses if they wore the monitors for at least 3 weekdays and 1 weekend day [31].

Descriptive statistics (means, frequencies) were used to determine the prevalence of co-participation in this sample and Pearson's correlation coefficient examined the association between mothers' and children's physical activity. Separate multivariate linear regression analyses assessed the association between the five coparticipatory activities and mothers' and children's weekday and weekend day MVPA and LMVPA. Regression analyses outcome variables are expressed in minutes/day and were adjusted for mothers' or children's accelerometer wear time during the weekday/weekend day, sex of the child, maternal education and clustering by preschool the child attended. Data were analysed using Stata 12 [32].

\section{Results}

From the original sample, 51 participants $(28 \%)$ did not have sufficient accelerometry data $(n=6$ mothers with incomplete data; $n=45$ children with incomplete data) and a further $12(6 \%)$ did not have complete questionnaire data. Additionally, two fathers filled out the questionnaires and thus were excluded from these analyses. This left a total of 123 (66\%) mother-child pairs to be included in the analyses. Table 1 outlines demographic characteristics of participants. On average, children were just over 5.4 years of age and $50 \%$ were boys. All children met physical activity recommendations of at least 60 min MVPA/day [33] when their physical activity level was averaged across all valid days monitored, but only $24 \%$ did so when their physical activity was assessed against guidelines for every day monitored. Mothers were highly educated $(74 \%$ with university degree or higher) and 36\% met the adult physical activity recommendations [34]. Mothers and children's weekday and weekend MVPA was significantly correlated $(r=0.23$, $p<0.05$ weekday; $r=0.18 p<0.05$ weekend) however their weekday and weekend day LMVPA was not.

Table 2 outlines the prevalence of mother-child coparticipation in the five activities assessed and the associations between co-participation and children's MVPA and LMVPA on weekdays and weekend days. For most co-participatory variables, few (8-15\%) mothers reported engaging in the activities with their child 'often/always' or 'greater than once per week'. However, the majority of mothers $(65 \%)$ reported using active transport for short trips with their child. On weekdays, attending a park, playground, beach or similar more than once per week was negatively associated with children's MVPA $(\beta=-19.79[-30.40,-9.18])$ and LMVPA $(\beta=-29.85$ $[-58.97,-0.73])$, while walking or cycling for short trips was positively associated with children's MVPA $(\beta=15.73[6.48,24.99])$. On weekends, walking or cycling with their child in their free time 'sometimes' or 'often/always' was positively associated with children's MVPA $(\beta=9.60[0.96,18.24]$ 'Sometimes'; $\beta=15.77$ ([3.54, 28.00] 'Often/always') and LMVPA $(\beta=24.09$ $[9.41,38.78]$ 'Sometimes'). Additionally, going to an indoor play centre together 1-3 times/month was negatively associated with children's weekend MVPA $(\beta=-17.70[-29.15,-6.24])$.

Table 3 outlines the associations between coparticipation and mothers' MVPA and LMVPA. Going to an indoor recreation centre with their child more than once per once or more per week was associated with lower maternal weekday LMVPA $(\beta=-48.95$ $[-81.31,-16.59])$ whilst walking or cycling with their child in their free time 'sometimes' $(\beta=8.31[0.04$, $16.58])$ or 'often/always' $(\beta=21.29[8.19,34.39])$ was positively associated with mothers weekend MVPA. 
Table 1 Demographic characteristics and objectively assessed physical activity levels of children and mothers

\begin{tabular}{|c|c|}
\hline \multicolumn{2}{|l|}{ Participant characteristic } \\
\hline \multicolumn{2}{|l|}{ Children } \\
\hline Age (years) & $5.4(0.32)$ \\
\hline Child sex (\% male) & $50.0 \%$ \\
\hline Attending preschool full-time (5 days/week) & $100.0 \%$ \\
\hline Presence of siblings in home (\% yes) & $88.6 \%$ \\
\hline Predominant language spoken at home (\% Dutch) & $97.6 \%$ \\
\hline \multicolumn{2}{|l|}{ Accelerometer wear time (mins/day) } \\
\hline Weekdays & $\begin{array}{l}701.8 \\
(57.7)\end{array}$ \\
\hline Weekends & $\begin{array}{l}678.7 \\
(91.6)\end{array}$ \\
\hline \multicolumn{2}{|l|}{ Physical activity (mins/day) } \\
\hline Weekday MVPA & $\begin{array}{l}85.2 \\
(26.4)\end{array}$ \\
\hline Weekend MVPA & $\begin{array}{l}81.0 \\
(32.7)\end{array}$ \\
\hline Weekday LMVPA & $\begin{array}{l}359.1 \\
(52.7)\end{array}$ \\
\hline Weekend LMVPA & $\begin{array}{l}345.3 \\
(67.7)\end{array}$ \\
\hline $\begin{array}{l}\text { Proportion meeting children's physical activity } \\
\text { recommendations ( } 60 \text { mins/day on average day) }\end{array}$ & $100.0 \%$ \\
\hline $\begin{array}{l}\text { Proportion meeting children's physical activity } \\
\text { recommendations ( } 60 \text { mins/day everyday) }\end{array}$ & $24.0 \%$ \\
\hline \multicolumn{2}{|l|}{ Mothers } \\
\hline Age (years) & $34.9(3.7)$ \\
\hline \multicolumn{2}{|l|}{ Body mass index } \\
\hline Underweight $\left(<18.5 \mathrm{~kg} / \mathrm{m}^{2}\right)$ & $5.38 \%$ \\
\hline Healthy $\left(18.5-24.9 \mathrm{~kg} / \mathrm{m}^{2}\right)$ & $72.3 \%$ \\
\hline Overweight (25.0-29.9 kg/m²) & $17.7 \%$ \\
\hline Obese $(>30$ kg/m²) & $4.6 \%$ \\
\hline \multicolumn{2}{|l|}{ Education } \\
\hline Low (Secondary school or less) & $2.4 \%$ \\
\hline Mid (vocational trade/certificate) & $23.6 \%$ \\
\hline High (university degree or higher) & $74.0 \%$ \\
\hline \multicolumn{2}{|l|}{ Accelerometer wear time (mins/day) } \\
\hline Weekdays & $\begin{array}{l}901.4 \\
(84.5)\end{array}$ \\
\hline Weekends & $\begin{array}{l}832.4 \\
(88.9)\end{array}$ \\
\hline \multicolumn{2}{|l|}{ Physical activity (mins/day) } \\
\hline Weekday MVPA & $\begin{array}{l}30.5 \\
(22.9)\end{array}$ \\
\hline Weekend MVPA & $\begin{array}{l}25.3 \\
(21.7)\end{array}$ \\
\hline Weekday LMVPA & $\begin{array}{l}380.0 \\
(93.9)\end{array}$ \\
\hline
\end{tabular}

Table 1 Demographic characteristics and objectively assessed physical activity levels of children and mothers (Continued)

\begin{tabular}{cc}
\hline Weekend LMVPA & 368.9 \\
& $(93.5)$ \\
Proportion meeting adult physical activity & $35.8 \%$ \\
recommendations per week (150 mins + MVPA per week) & \\
\hline
\end{tabular}

\section{Discussion}

There is increasing interest in identifying strategies to increase physical activity amongst both parents and young children $[9,21]$. This was the first study to report the prevalence of maternal-child co-participation in several age-appropriate activities and to examine the association between maternal-child co-participation and mothers' and their children's MVPA. The findings from this study are a platform from which we can build our understanding of family physical activity participation and identify strategies that may be effective at concurrently increasing physical activity in young families.

Overall, maternal-child co-participation was low for most of the variables assessed with approximately $1 / 3$ to $1 / 2$ of participants reporting that they 'never' or 'seldom' participated in the activity with their child, or did the activity less than once per month. This is consistent with other research which suggests parents and primary school-aged children engage in more sedentary behaviours together compared to active ones [12], and highlights a potential opportunity to promote coparticipation to families with young children. The only exception among the variables assessed was in the use of active transport for short trips. The majority (65\%) of mothers reported walking or cycling with their child was the main form of transport for distances less than $1 \mathrm{~km}$. While this is comparable to that found in British families [35], it is likely greater than what would be observed in other countries [36]. Nonetheless, the higher prevalence of this co-participatory activity compared to the others may suggest that walking or cycling for short trips is perceived to be feasible by both mothers and children. Thus it may hold potential for incorporating into familybased intervention programs.

A novel aspect of this work was that it examined associations between co-participation and both mothers' and their children's MVPA, which may be important for reciprocal reinforcement of health behaviours within families [37]. Only walking or cycling together in their free time was associated with higher MVPA in both parties, and this occurred on weekends only. Given that most children in Belgium attend preschool full time [29], mothers and children may have more time during weekends to engage in this behaviour compared to weekdays. Regardless, given the association observed here, familybased intervention programs may consider specifically incorporating leisure time walking/cycling as a strategy to 
Table 2 Prevalence of maternal-child co-participation and associations with children's LMVPA and MVPA on weekdays and weekend days $^{*}$

\begin{tabular}{|c|c|c|c|c|c|}
\hline Co-participatory activity & $\begin{array}{l}\text { Prevalence } \\
\text { N (\%) }\end{array}$ & $\begin{array}{l}\text { Children's Weekday } \\
\text { MVPA } \\
\beta(95 \% \text { Cl) }\end{array}$ & $\begin{array}{l}\text { Children's Weekday } \\
\text { LMVPA } \\
\beta(95 \% \text { Cl) }\end{array}$ & $\begin{array}{l}\text { Children's Weekend } \\
\text { MVPA } \\
\beta(95 \% \mathrm{Cl})\end{array}$ & $\begin{array}{l}\text { Children's Weekend } \\
\text { LMVPA } \\
\beta(95 \% \text { Cl) }\end{array}$ \\
\hline
\end{tabular}

Walking or cycling with their child in their free time

$\begin{array}{llllll}\text { Never/seldom } & 41(33 \%) & \text { Ref. } & \text { Ref. } & \text { Ref. } & \text { Ref. } \\ \text { Sometimes } & 72(59 \%) & 3.04(-6.26,12.37) & 6.21(-12.66,25.08) & \mathbf{9 . 6 0 ( 0 . 9 6 , ~ 1 8 . 2 4 )} & \mathbf{2 4 . 0 9}(\mathbf{9 . 4 1 , ~ 3 8 . 7 8 )} \\ \text { Often/always } & 10(8 \%) & 5.43(-7.19,18.04) & 8.26(-20.73,37.25) & \mathbf{1 5 . 7 7}(\mathbf{3 . 5 4}, \mathbf{2 8 . 0}) & 16.68(-9.88,43.27)\end{array}$

Playing sport with their child

$\begin{array}{llllll}\text { Never/seldom } & 52(42 \%) & \text { Ref. } & \text { Ref. } & \text { Ref. } & \text { Ref. } \\ \text { Sometimes } & 57(46 \%) & -3.76(-16.19,8.66) & -4.21(-25.6,17.16) & -9.51(-22.07,3.05) & -8.04(-28.47,12.39) \\ \text { Often/always } & 14(11 \%) & -9.07(-23.56,5.40) & -15.53(-44.02,12.97) & -11.78(-26.19,2.63) & -10.45(-26.18,5.29)\end{array}$

Going to the park, playground, beach or similar with their child

\begin{tabular}{|c|c|c|c|c|c|}
\hline$<$ once per month & $46(37 \%)$ & Ref. & Ref. & Ref. & Ref. \\
\hline $\begin{array}{l}1-3 \text { times per } \\
\text { lonth }\end{array}$ & $58(47 \%)$ & $-8.31(-19.99,3.37)$ & $-10.44(-32.18,11.30)$ & $5.74(-9.39,20.88)$ & $9.30(-20.62,39.21)$ \\
\hline$\geq$ once per week & $19(15 \%)$ & $-19.79(-30.40,-9.18)$ & $-29.85(-58.97,-0.73)$ & $-12.04(-31.61,7.53)$ & $-27.36(-68.21,13.49$ \\
\hline
\end{tabular}

Frequency of going to an indoor recreation centre with their child

\begin{tabular}{|c|c|c|c|c|c|}
\hline$<$ once per month & 60 (49\%) & Ref. & Ref. & Ref. & Ref. \\
\hline $\begin{array}{l}1-3 \text { times per } \\
\text { month }\end{array}$ & $26(21 \%)$ & $1.40(-10.74,13.53)$ & $8.55(-19.80,36.90)$ & $-17.70(-29.15,-6.24)$ & $-21.79(-52.93,9.34)$ \\
\hline$\geq$ once per week & 37 (30\%) & $2.16(-2.71,7.02)$ & $1.11(-14.16,16.40)$ & $-6.91(-21.78,7.95)$ & $-12.14(-34.36,10.08)$ \\
\hline
\end{tabular}

Mode of transport used for short trips $(<1 \mathrm{~km})$ with their child

$\begin{array}{llllll}\text { Inactive } & 43(35 \%) & \text { Ref. } & \text { Ref. } & \text { Ref. } & \text { Ref. } \\ \text { Active } & 80(65 \%) & \mathbf{1 5 . 7 3}(\mathbf{6 . 4 8 , 2 4 . 9 9 )} & 12.64(-8.58,33.84) & 2.09(-9.21,13.40) & -4.53(-24.02,14.97)\end{array}$

"Multi-variate linear regression models adjusted for maternal education, child's sex, accelerometer wear time and clustering by preschool attended; Bolded results are significant at $p<0.05$

increase weekend MVPA in both mothers and their children. However, given only one common co-participatory behaviour was observed, a diverse range of coparticipatory behaviours, including those not assessed in this study, might need to be promoted to families to effectively increase physical activity in both parties.

Walking or cycling for short trips was positively associated with children's weekday MVPA. Active travel has previously been associated with greater physical activity in children [35], and as children in the current sample all attended preschool full-time, it is possible that much of the active travel for short trips occurred as active transport to preschool. Thus, efforts to promote active transport to preschool and provide supportive infrastructure to make this feasible for families may increase MVPA in children. However, contrary to hypotheses, frequently going to the park or similar together on weekdays and occasionally going to an indoor play centre together on weekends was associated with lower MVPA in children, inconsistent with previous research [38]. As some research has found that the presence of a parent/ adult was associated with lower physical activity amongst children in parks [39], it is possible that depending on the context and interaction, parents can actually reduce children's physical activity. Thus, understanding the nature and context of the co-participation between parents and children may be crucial. Additionally, frequently attending an indoor play centre together on weekdays was associated with lower LMVPA in mothers. Whilst it isn't clear why this association was observed, it is possibly that by taking their child to the centre, mothers may actually be replacing time where they might otherwise have been active.

Although this study provides a novel examination of mother-child co-participation in physical activity, several limitations must be acknowledged. First, only five purpose-designed co-participatory variables were assessed. Although these variables capture the main forms of physical activity undertaken for preschool aged children, it is possible that other co-participatory activities not assessed in this study may be associated with mothers' or children's MVPA. Additionally, the measures used were purpose designed given the lack of coparticipation measures available at the time of data collection. This may have resulted in over- or underestimation of true co-participation as mothers were not 
Table 3 Associations between maternal-child co-participation and mothers' MVPA and LMVPA on weekdays and weekend days ${ }^{*}$

\begin{tabular}{|c|c|c|c|c|}
\hline Co-participatory activity & $\begin{array}{l}\text { Mothers' Weekday MVPA } \\
\beta(95 \% \mathrm{Cl})\end{array}$ & $\begin{array}{l}\text { Mothers' Weekday LMVPA } \\
\beta(95 \% \mathrm{Cl})\end{array}$ & $\begin{array}{l}\text { Mothers' Weekend MVPA } \\
\beta(95 \% \mathrm{Cl})\end{array}$ & $\begin{array}{l}\text { Mothers' Weekend LMVPA } \\
\beta(95 \% \mathrm{Cl})\end{array}$ \\
\hline \multicolumn{5}{|c|}{ Walking or cycling with their child in their free time } \\
\hline Never/seldom & Ref. & Ref. & Ref. & Ref. \\
\hline Sometimes & $1.23(-6.75,9.22)$ & $12.41(-23.23,48.04)$ & $8.31(0.04,16.58)$ & $14.27(-28.13,56.68)$ \\
\hline Often/always & $19.25(-2.02,40.52)$ & $47.20(-20.20,114.59)$ & $21.29(8.19,34.39)$ & $49.20(-13.04,111.44)$ \\
\hline \multicolumn{5}{|c|}{ Playing sport with their child } \\
\hline Never/seldom & Ref. & Ref. & Ref. & Ref. \\
\hline Sometimes & $4.48(-5.56,14.53)$ & $3.82(-33.14,40.77)$ & $-4.08(-12.77,4.61)$ & $-14.75(-51.12,21.62)$ \\
\hline Often/always & $-2.76(-22.69,17.18)$ & $14.49(-50.53,79.51)$ & $-10.07(-24.89,4.76)$ & $-25.04(-63.23,13.15)$ \\
\hline \multicolumn{5}{|c|}{ Going to the park, playground, beach or similar with their child } \\
\hline$<$ once per month & Ref. & Ref. & Ref. & Ref. \\
\hline 1-3 times per month & $-0.88(-11.73,9.96)$ & $3.06(-48.63,54.75)$ & $0.74(-10.55,12.04)$ & $21.63(-19.11,62.38)$ \\
\hline$\geq$ once per week & $-13.28(-27.11,0.55)$ & $-6.03(-73.28,60.68)$ & $-7.80(-19.30,3.70)$ & $7.34(-35.91,50.59)$ \\
\hline \multicolumn{5}{|c|}{ Frequency of going to an indoor recreation centre with their child } \\
\hline$<$ once per month & Ref. & Ref. & Ref. & Ref. \\
\hline $1-3$ times per month & $-0.74(-13.68,12.20)$ & $3.94(-51.22(59.11)$ & $-4.22(-12.77,4.61)$ & $-24.35(-69.32,20.61)$ \\
\hline$\geq$ once per week & $-0.78(-8.26,6.69)$ & $-48.95(-81.31,-16.59)$ & $-3.68(-12.49,5.13)$ & $-31.49(-82.21,19.22)$ \\
\hline \multicolumn{5}{|c|}{ Mode of transport used for short trips $(<1 \mathrm{~km})$ with their child } \\
\hline Inactive & Ref. & Ref. & Ref. & Ref. \\
\hline Active & $8.05(-2.08,18.18)$ & $27.29(-5.14,59.27)$ & $4.74(-3.63,13.12)$ & $26.87(-1.23,54.96)$ \\
\hline
\end{tabular}

"Multi-variate linear regression models, adjusted for maternal education, accelerometer wear time and clustering by preschool attended; Bolded results are significant at $p<0.05$

specifically asked to consider only the time that they were actively participating with their child. It is recommended that a comprehensive evaluation of coparticipatory measures is developed and validated for use in future research. Finally, the sample was limited in size, cross-sectional in nature and largely relied on a convenience sample of tertiary educated mothers. Thus, investigations of parent-child co-participation should be replicated in a larger, diverse sample, include fathers and utilise longitudinal designs.

\section{Conclusions}

In summary, this study was the first to describe coparticipation in physical activity among mothers and their preschool children and associations with mother and child physical activity. Based on the findings, opportunities exist to increase co-participation in motherchild pairs. Additionally, the association between coparticipation and physical activity of mothers and children may be activity-specific and differ on weekdays compared to weekends. However, walking or cycling in leisure time might be a promising strategy to increase physical activity of both family members. The findings from this study are a platform from which we can build our understanding of family-based physical activity and identify strategies that can be used in intervention programs to concurrently increase physical activity in mothers and young children.

\section{Acknowledgements}

The lead author was supported by a Deakin University Postgraduate Research Scholarship (International). The third author is supported by an Australian Research Council Future Fellowship (FT130100637) and an Honorary Heart Foundation Future Leader Fellowship (100370). The authors would like to thank Eveline Van Cauwenberghe for data collection and project management.

Funding

None.

Availability of data and materials

The datasets analysed during the current study are available from the corresponding author on reasonable request.

\section{Authors' contributions}

GC, EDD, and $\mathrm{JH}$ conceptualised the idea for the study. JH analysed the data and drafted the article. GC, EDD assisted with data analysis and interpretation. All authors revised the manuscript for important intellectual content, agree to be accountable for all aspects of the work and gave approval for the final version to be published.

\section{Competing interests}

The authors declare that they have no competing interests.

Consent for publication

Not applicable. 


\section{Ethics approval and consent to participate}

Ethics approval for this study was obtained from the Ethics Committee of the University Hospital of Ghent (EC/2006/476). All parents provided written informed consent for themselves and their child to take part in the study.

\section{Publisher's Note}

Springer Nature remains neutral with regard to jurisdictional claims in published maps and institutional affiliations.

\section{Author details}

'Institute for Physical Activity and Nutrition (IPAN), School of Exercise and Nutrition Sciences, Deakin University, Geelong, Australia. ${ }^{2}$ School of Science and Health, Western Sydney University, Locked Bag 1797, Penrith, NSW 2150, Australia. ${ }^{3}$ Department of Movement and Sport Sciences, Ghent University, Watersportlaan 2, Ghent, Belgium.

\section{Received: 4 September 2016 Accepted: 12 May 2017}

Published online: 25 May 2017

\section{References}

1. Bauman AE. Updating the evidence that physical activity is good for health: an epidemiological review 2000-2003. J Sci Med Sport. 2004;7(Supplement 1):6-19.

2. Timmons BW, LeBlanc AG, Carson V, Gorber SC, Dillman C, Janssen I, Kho ME, Spence JC, Stearns JA, Tremblay MS. Systematic review of physical activity and health in the early years (aged 0-4 years). Appl Physiol Nutr Metab. 2012;37:773-92.

3. Bellows-Riecken $\mathrm{KH}$, Rhodes RE. A birth of inactivity? A review of physical activity and parenthood. Prev Med. 2008;46(2):99-110.

4. Adamo KB, Langlois KA, Brett KE, Colley RC. Young children and parental physical activity levels: findings from the Canadian health measures survey. Am J Prev Med. 2012:43(2):168-75.

5. Hnatiuk J, Salmon J, Hinkley T, Okely A, Trost SG. A review of preschool children's physical activity and sedentary time using objective measures. Am J Prev Med. 2014:47(4):487-97.

6. Australian Bureau of Statistics. Australian Health Survey: Physical Activity Children 5-17 years. [http://www.abs.gov.au/ausstats/abs@.nsf/Lookup/ 462FBA87B642FCA4CA257BAC0015F3CE?opendocument]. Accessed 22 May 2017.

7. Troiano RP, Berrigan D, Dodd KW, Mâsse LC, Tilert T, McDowell M. Physical activity in the United States measured by accelerometer. Med Sci Sports Exerc. 2008:40(1):181

8. Biddle SJH, Gorely T, Stensel DJ. Health-enhancing physical activity and sedentary behaviour in children and adolescents. J Sports Sci. 2004;22(8):679-701.

9. Carson V, Rosu A, Janssen I. A cross-sectional study of the environment, physical activity, and screen time among young children and their parents. BMC Public Health. 2014;14(1):61.

10. Taylor WC, Baranowski T, Sallis JF. Family determinants of childhood physical activity: a social cognitive model. In: Dishman RK, editor. Advances in Exercise adherence. Champaign: Human Kinetics; 1994.

11. Morgan PJ, Young MD, Smith JJ, Lubans DR. Targeted health behavior interventions promoting physical activity: a conceptual model. Exerc Sport Sci Rev. 2016:44(2):71-80.

12. Dunton GF, Liao Y, Almanza E, Jerrett M, Spruijt-Metz D, Chou C-P, Pentz MA. Joint physical activity and sedentary behavior in parent-child pairs. Med Sci Sports Exerc. 2012;44(8):1473-80.

13. Lee SM, Nihiser A, Strouse D, Das B, Michael S, Huhman M. Correlates of children and parents being physically active together. J Phys Act Health. 2010;7(6):776-83.

14. Ploeg KAV, Maximova KP, Kuhle SMDP, Simen-Kapeu AMDP, Veugelers PJP The importance of parental beliefs and support for physical activity and body weights of children: a population-based analysis. Can J Public Health. 2012;103(4):277-81.

15. Beets MW, Foley JT. Association of Father Involvement and Neighborhood Quality with Kindergartners' physical activity: a multilevel structural equation model. Am J Health Promot. 2008:22(3):195-203.

16. Hinkley T, Salmon J, Okely AD, Hesketh K, Crawford D. Correlates of preschool Children's physical activity. Am J Prev Med. 2012:43(2):159-67.

17. Cleland V, Timperio A, Salmon J, Hume C, Telford A, Crawford D. A longitudinal study of the family physical activity environment and physical activity among youth. Am J Health Promot. 2011;25(3):159-67.
18. Abbott G, Hnatiuk J, Timperio A, Salmon J, Best K, Hesketh KD. Crosssectional and Longitudinal Associations Between Parents' and Preschoolers' Physical Activity and TV Viewing: The HAPPY Study. J Phys Act Health. 2015; 13: $269-274$.

19. Hesketh KR, Goodfellow L, Ekelund U, McMinn AM, Godfrey KM, Inskip HM, Cooper C, Harvey NC, van Sluijs EMF. Activity levels in mothers and their preschool children. Pediatrics. 2014;133(4):e973-80.

20. Ruiz R, Gesell SB, Buchowski MS, Lambert W, Barkin SL. The relationship between Hispanic parents and their preschool-aged Children's physical activity. Pediatrics. 2011;127(5):888-95.

21. Uijtdewilligen L, Peeters GMEE, van Uffelen JGZ, Twisk JWR, Singh AS, Brown WJ. Determinants of physical activity in a cohort of young adult women. Who is at risk of inactive behaviour? J Sci Med Sport. 2015;18(1):49-55.

22. Alderman BL, Benham-Deal TB, Jenkins JM. Change in parental influence on children's physical activity over time. J Phys Act Health. 2010;7:60-7.

23. Pi-Sunyer FX, Becker DM, Bouchard C, Carleton R, Colditz G, Dietz W, Foreyt J, Garrison R, Grundy S, Hansen B. Clinical guidelines on the identification, evaluation, and treatment of overweight and obesity in adults. Am J Clin Nutr. 1998;68(4):899-917.

24. Hinkley T, Salmon J, Okely AD, Crawford D, Hesketh K. Preschoolers' physical activity, screen time, and compliance with recommendations. Med Sci Sports Exerc. 2012:44(3):458-65.

25. Pate RR, Almeida MJ, Mclver KL, Pfeiffer KA, Dowda M. Validation and calibration of an accelerometer in preschool children. Obesity. 2006:14(11):2000-2006.

26. Canadian Society for Exercise Physiology. Canadian physical activity guidelines for the early years. [http://www.csep.ca/english/view.asp? $x=804]$. Accessed 22 May 2017

27. Australian Department of Health and Ageing. Move and play every day: National physical activity recommendations for children (0-5 years). [http:// www.health.gov.au/internet/main/publishing.nsf/Content/health-pubh/thstrateg-phys-act-guidelines]. Accessed 22 May 2017.

28. Hnatiuk JA, Ridgers ND, Salmon J, Hesketh KD. Maternal correlates of young children's physical activity across periods of the day. J Sci Med Sport. 2017; 20:178-183

29. OECD Family Database. Enrolment in childcare and preschool. [http://www. oecd.org/els/family/database.htm]. Accessed 22 May 2017.

30. Freedson PS, Melanson E, Sirard J. Calibration of the computer science and applications, inc. accelerometer. Med Sci Sports Exerc. 1998;30(5):777-81.

31. Matthews CE, Ainsworth BE, Thompson RW, Bassett DRJ. Sources of variance in daily physical activity levels as measured by an accelerometer. Med Sci Sports Exerc. 2002;34(8):1376-81.

32. StataCorp. Stata Statistical Software: Release 12. College Station, TX: StataCorp LP; 2011. http://www.stata.com/support/faqs/resources/citingsoftware-documentation-fags/.

33. Australian Department of Health and Ageing. Australia's physical activity recommendations for 5-12 year olds. [http://www.health.gov.au/internet/ main/publishing.nsf/content/health-pubhlth-strateg-phys-actguidelines\#apaadult]. Accessed 22 May 2017.

34. Australian Department of Health and Ageing. National Physical Activity Guidelines for Adults. [http://www.health.gov.au/internet/main/publishing. nsf/content/health-pubhlth-strateg-phys-act-guidelines\#apaadult]. Accessed 22 May 2017.

35. van Sluiis EMF, McMinn AM, Inskip HM, Ekelund U, Godfrey KM, Harvey NC, Griffin SJ. Correlates of light and moderate-to-vigorous objectively measured physical activity in four-year-old children. PLoS One. 2013:8(9):e74934.

36. Sirard JR, Slater ME. Walking and bicycling to school: a review. Am J Lifestyle Med. 2008;2(5):372-96.

37. Morgan PJ, Lubans D, Callister R, Okely AD, Burrows T, Fletcher R, Collins C. The 'healthy dads, healthy kids' randomized controlled trial: efficacy of a healthy lifestyle program for overweight fathers and their children. Int J Obes. 2011:35(3):436-47.

38. Cerin E, Baranowski T, Barnett A, Butte N, Hughes S, Lee RE, Mendoza JA, Thompson D, O'Connor TM. Places where preschoolers are (in) active: an observational study on Latino preschoolers and their parents using objective measures. Int J Behav Nutr Phys Act. 2016;13(1):1-12.

39. Floyd MF, Bocarro JN, Smith WR, Baran PK, Moore RC, Cosco NG, Edwards MB, Suau LJ, Fang K. Park-based physical activity among children and adolescents. Am J Prev Med. 2011:41(3):258-65. 